Single Polymer Composites Made of Melt-blown PP Mats and the Modelling of the Uniaxial Tensile Behaviour by the Fibre Bundle Cells Method Virag Á. D., Kara Y., Vas L. M., Molnár K.

Accepted for publication in Fibers and Polymers

Published in 2021

DOI: https://doi.org/10.1007/s12221-021-0038-6 


\title{
Single polymer composites made of melt-blown PP mats, and the modelling of the uniaxial tensile behaviour by the Fibre Bundle Cells method
}

\author{
Ábris Dávid VIRÁGa ${ }^{\mathrm{a}}$, Yahya KARA ${ }^{\mathrm{a}}$, László Mihály VAS ${ }^{\mathrm{a}}$, Kolos MOLNÁR ${ }^{\mathrm{a}, b^{*}}$ \\ ${ }^{a}$ Department of Polymer Engineering, Faculty of Mechanical Engineering, Budapest University \\ of Technology and Economics, Müegyetem rkp. 3. H-1111, Budapest, Hungary \\ ${ }^{\mathrm{b}}$ MTA-BME Research Group for Composite Science and Technology, Müegyetem rkp. 3., H- \\ 1111, Budapest, Hungary \\ *molnar@pt.bme.hu
}

\begin{abstract}
In this study, we generated polypropylene fibre mats via melt blowing (average diameter: $1.03 \mu \mathrm{m})$, and then produced self-reinforced composites using hot compaction and investigated the effect of the processing temperature. Scanning electron microscopy (SEM) revealed that our composites had good consolidation, low void content and besides, the fibres and the matrix were clearly distinguishable. The differential scanning calorimetry (DSC) tests showed that the composites are easy to recycle by re-melting. The tensile tests of the melt-blown nonwovens and the produced composites revealed that increasing the temperature of hot compaction results in embrittlement (from ductile to brittle) of the samples, which means higher specific tensile forces and smaller deformations. Using the Fibre Bundle Cells modelling method, we developed a phenomenological, analytical model to describe the total tensile curve (both the deformation and the failure behaviour) and analyse the tensile properties of these hot compacted composites. The determination coefficients $\left(R^{2}\right)$ between the modelled and measured force were larger than 0.99 and the relative mean squared error (RMSE) values (related to the measured maximum force
\end{abstract}


value) were smaller than $3 \%$ in every examined case, which indicated good modelling. Hence, the FBC model not only described the tensile behaviour of the nonwovens well, but it was also applicable for the composites.

Keywords: Fibre Bundle Cells modelling, nonwoven, melt blowing, polypropylene, selfreinforced composite

\section{Introduction}

In the field of composites there is a growing demand for the use of lightweight, environmentally friendly, recyclable thermoplastic composites. Nowadays, there are many ways to produce this kind of material; one of them is to produce single-polymer (or self-reinforced) composite (SPC) materials [1-4]. The self-reinforcement technique was first introduced in the 1970s for PE [5] and also reported by other researchers to be highly effective for other polymers such as PP [6] and PET [4]. In single-polymer composites (also known as homocomposites, all (the same) composites, self-reinforced composites or homogeneous composites) the fibre and the matrix are of the same polymer [5]. SPCs usually have no interfacial issues since the reinforcement and the matrix are chemically compatible [7]. Furthermore, SPCs can be completely melted and when it comes to recycling, this property is a great advantage compared to, for example, carbon or glass fibre reinforced composites, whose mechanical and thermal recycling still causes environmental problems [8]. In the near future, these SPCs and melt-blown fibre mats can significantly contribute to a wide range of applications, for example tissue scaffolds [9], filtering applications [10], superhydrophilic membranes [11,12], sound absorption [13] and ductile \& impact-resistant components $[14,15]$.

There are several methods to produce SPCs, e.g. by hot compaction, film-stacking or coextrusion. Hot compaction is a technology in which a single component, usually oriented fibres, is pressed into a composite sheet with the proper temperature and pressure [16]. As a result, the fibres 
partially melt, and then during cooling, the melted outer shell of the fibres becomes the matrix, and the unmelted core of the fibres function as the reinforcing material. This is influenced by the local temperature and pressure distribution and therefore it is a challenge to set the volume fraction of the molten polymer, and undesired macro-inhomogeneity of the structure can occur. The main difference compared to the other processes is that in hot compaction, both the matrix and the reinforcing material are derived from the same material. The disadvantage of this method is the narrow processing window $[8,16,17]$.

Polypropylene (PP) fibres and related composites are of great interest in the academic and the industrial sector, because PP is one of the most common polymers, and is preferred in a wide range of products. PP is a commodity plastic with outstanding chemical and moisture resistance, low density, good processability, high ductility, and relatively low cost [18-20].

Some articles examine the production and testing of self-reinforced PP composites produced by hot compaction [21-23]; however, the number of articles focusing on hot-compacted, selfreinforced composites made from melt-blown nonwovens is relatively small [24]. More and more articles focus on the production and testing of hot-compacted polylactic acid (PLA) nonwovens due to their biodegradability $[25,26]$.

Melt blowing is a simple and versatile method to produce ultrafine fibres directly from polymer melt. Fibres are continuously generated by extruding a polymer melt through a capillary die and drawing these exiting fibres with the flow of pressurized hot air. A melt-blown fibre web is formed directly from a molten polymer at a high production rate; this gives melt blowing a distinct cost advantage in comparison with other microfibre and nanofibre generating techniques [27-29]. 
There has been very limited research on fine fibre mat reinforced thermoplastic composites so far. However, electrospinning is the most widely used method of generating nonwovens to produce such composite structures. Somord et al. [26] investigated the mechanical and thermal properties of SPCs produced by the hot compaction of PLA electrospun nanofibres. Their results demonstrated that neat PLA films showed a lower glass transition temperature and a much lower degree of crystallinity than electrospun PLA fibre mats and PLA single polymer nanocomposites (SPnC). In the case of PLA-SPnCs, the crystallinity of all SR nanocomposites was increased (from $16 \%$ to $35-44 \%$ ) without cold crystallization after hot compaction. The melting peaks of PLA SPnCs were shifted to $156-157{ }^{\circ} \mathrm{C}$ from $149{ }^{\circ} \mathrm{C}$. Their findings showed that the tensile strength and elastic modulus of the PLA SPnC (at 20 s compaction time: ultimate tensile stress $=77.5 \mathrm{MPa}, \mathrm{E}=3.2 \mathrm{GPa}$ ) improved compared to the properties of the neat PLA film (ultimate tensile stress $=49.9 \mathrm{MPa}, \mathrm{E}=2.8 \mathrm{GPa}$ ). Matabola et. al. [30] investigated the influence of PMMA nanofibres of different diameters and fibre weight contents of $5 \mathrm{wt} \%$ and $10 \mathrm{wt} \%$ on the dynamic mechanical properties of PMMA SPnCs. The PMMA nanocomposites reinforced with nanofibres of smaller diameters showed a great improvement in stiffness compared to the nanocomposite reinforced with the nonwoven mat of larger diameter fibres at $10 \mathrm{wt} \%$ nanofibre loading. The stiffness of all the SPnCs were higher than that of the neat PMMA matrix. They also reported that at $10 \mathrm{wt} \%$ nanofibre loading, the stiffness and glass transition temperature of PMMA SPnCs increased by $83 \%$ and by $10^{\circ} \mathrm{C}$, respectively.

Vadas et. al. [14] produced self-reinforced PLA (SR-PLA) composites by the hot compaction of PLA melt-blown nonwovens (average diameter: $2-14 \mu \mathrm{m}$ ). They investigated the effect of annealing on the morphological, thermal and mechanical properties of the PLA mat and the SRPLA composite. The crystallinity and tensile strength of the PLA mat increased with annealing $\left(85{ }^{\circ} \mathrm{C}\right.$ for $2 \mathrm{~h}$ ) from $26 \%$ to $55 \%$ and $7.4 \mathrm{MPa}$ to $8.9 \mathrm{MPa}$, respectively, whereas the elastic modulus of the annealed PLA mat became much less than that of the non-annealed PLA mat. 
They reported that the mechanical properties of the PLA mat (annealed fibres, compacted for 30 s) were better than those of SR-PLA specimens made from non-annealed fibre mats. The thermal treatment of the melt-blown PLA mat increased the tensile strength of the SR-PLA composite about 47\% (43 $\pm 9 \mathrm{MPa})$ when compacted for 30s. Mijares et. al. [24] investigated PP composites reinforced with commercial woven and nonwoven (spunbonded + melt-blown) fabric, which were produced by hot compaction and film stacking. Their result showed that the reinforcement of the PP matrix with nonwoven PP fabrics did not result in any significant improvement in mechanical properties. On the other hand, they reported that the hot-compacted composites containing simultaneously woven and nonwoven fabrics had in enhanced tensile, impact and fracture properties compared to the film stacked composites.

There are several different, usually numerical methods, including finite element analysis [31] to describe and predict the deformation and failure processes of composites. The behaviour of a component under load can be described with dedicated material models. These models not only consider the fibrous, anisotropic structural properties, but can also describe the damage process of composite materials. One such method is fibre bundle cell-based (FBC) modelling [32-37]. The great advantage of the method is that it can model the statistical structural defects within the material and makes it possible to describe not only the deformation but also the failure process up to the breaking of the last working fibre. Moreover, this method does not require meshing, and requires far less computing than finite element models, therefore in simple cases, fibre bundle cell-based modelling can be performed relatively easily and quickly.

A limited number of studies has focused on SPCs made from nonwovens up to now. To the best of our knowledge, there have been no publications on the modelling of the tensile behaviour of SPCs made from nonwovens. In this study, we produced PP microfibre mats, then applied hot compaction at different temperatures to generate self-reinforced composites. We tested the 
uniaxial tensile behaviour of the samples and developed a phenomenological, analytical (FBC) model to describe the test results including deformation and failure behaviour.

\section{Theoretical}

\section{Fundamentals of Fibre Bundle Cells modelling}

The Fibre Bundle Cells (FBC) modelling method developed by Vas et al. [32-37] is a discrete element model that takes into account that the fibrous structure to be modelled is not a continuum structure, uses probability variables and can model the statistical structural defects of the material. It has the great advantage of describing not only deformation, but also the failure process.

The FBC model offers a set of mechanical modelling elements which can be connected in series and/or in parallel creating a network for describing the behaviour of fibrous structures and related composites. Hence, the FBC model describes the fibrous structure as a concentrated parameter network of such mechanical elements (fibre bundle cells) with discrete, statistical, linear or nonlinear characteristics.

The model assumes that the fibres of the material can be classified into groups based on their structural and mechanical similarities. Hence, fibre bundles of the same type of fibres can be constructed. They are classified based on their initial state (pre-stressed or not, oblique or not) and the environmental properties (gripping conditions) of the fibres. The fibres can be shifted along with their environment (or similar environment) as deformation occurs. As an ideally arranged fibre bundle is stretched in the fibre direction, the specific deformation of the fibre $(\varepsilon)$ is equal to the relative elongation of its environment $(u)$, which is the fibre bundle. In case of a disordered fibre bundle, or for non-ideal clamping, the fibres may have a different state and behaviour relative to their environment (e.g. pre-stressed, loose, wavy or not parallel to one another or slip out of the grip). In this case, the elongation of the given fibre depends on the tensile deformation of the fibre bundle $(u)$ as an environment, but usually differs from it, hence 
the specific fibre deformation is not equal to the relative fibre bundle deformation. Fibres in the same classes form a sub-fibre bundle (i.e., a fibre bundle cell). The system of fibre bundle cells produced in this way, parallel to the direction of stretching, models the structure and strength of the original bundle.

In the model system, four basic idealised fibre bundle cells (short: base bundle) are distinguished. Each of the base bundles is characterised by the fact that its fibres are perfectly flexible, i.e. they can only transmit tensile force, they are linearly elastic in terms of their tensile characteristics, and they break under the effect of the right amount of tensile force. The elongation at break $\left(\varepsilon_{B}\right)$, as well as the tensile stiffness $(K)$ of the fibres appear as probability variables in the model. The elongation at break $\left(\varepsilon_{B}\right)$ and the tensile breaking force $\left(F_{B}\right)$ of the fibres are directly proportional to each other, the proportionality factor between them being the tensile stiffness $(K)$. The four different base bundles are the following: E-bundle, EH-bundle, ES-bundle, and ET-bundle. Their schematics and main properties are shown in Figure 1 and Table 1, respectively. Idealized fibre bundles can be defined according to their deviation from the ideal. From a structural-mechanical point of view, the E-bundle is an ideal bundle, while the other three (EH, ES, ET) are intended to characterise some statistical defect in the mechanical state and/or the geometrical position and/or the gripping of the fibres of the tested fibrous material (Table 1). However, the fibres of the bundles are not the same as the fibres of the tested fibrous material. For example, in the case of a reinforcing fabric, the fibres of the bundles also contain the effect of the cross-connections or in the case of a composite sheet, the fibres of the bundles also contain the effect of the matrix material. We consider these effects via the model parameters of the bundle cells.

The E-bundle is a well-arranged, elastic, breakable bundle. Its fibres are straight, independent of each other, and parallel to each other and the direction of straining. They have an ideal grip at both ends (i.e. they do not slip out of the grip and do not break in the grip). They are not prestrained, hence they are stress-free, but not loose at zero strain. In the basic E-bundle the tensile 
force characteristic of the fibres is linear, but a nonlinear E-bundle can also be defined and used. In the latter case, there is a nonlinear functional relationship between force and displacement.

In the EH-bundle, the fibres may be crimped or pre-strained. In the ET-bundle, the fibres are oblique and in the ES-bundle, the fibres are not gripped at both ends, hence they can slip out of the grips or they can create fibre chains with slipping bonds; their damage mode can be either breakage or slippage.

Figure 1: The schematics of the base bundles [34]

Table 1: The main properties of the base bundles

We used a series of non-linear E-bundles to model the measured averaged tensile stress-strain or specific force-strain curves $(f(u))$ with the Fibre Bundle Cells (FBC) method. This means a kind of extending the measured numerical results to a special finite function series, whose terms are products of nonlinear functions (1):

$$
f_{\text {measured }}(u) \approx f_{\text {model }}(u)=\sum_{i=1}^{n} p_{i} f_{i}(u)=\sum_{i=1}^{n} p_{i} k_{i}(u) R_{i}(u)
$$

where $u$ is the tensile strain, and $p_{i}, f_{i}(u), k_{i}(u)$ and $R_{i}(u)$ are the weight, the specific force, the tensile characteristic and the reliability function of the $i^{\text {th }}$ model component $(i=1, \ldots, n)$, respectively. The latter two function can be given in the next forms $(2,3)$ :

$$
\begin{gathered}
k_{i}(u)=a_{i}\left(1-e^{-b_{i} u}\right)+c_{i} u \\
R_{i}(u)=1-Q_{i}(u)
\end{gathered}
$$


where $a_{i}, b_{i}$ and $c_{i}$ are the FBC model parameters and $Q_{i}(u)$ is the distribution function of the specific elongation at break.

Equation (2) is the force response of a simple Standard Solid model to a ramp-like strain stimulus, like in a tensile tests. On the other hand, it can include the expected tensile characteristics of the linear E-, EH-, and ET-bundles, hence the expected tensile processes of the EH and ET bundles can be approximate by a series of parallel connected nonlinear E-bundles.

Actually, the reliability function calculated by Equation (3) is the complement distribution function of the breaking strain of model fibres in the $i^{\text {th }}$ E-bundle, which is usually given by a simple normal distribution $\mathrm{N}\left(m, s^{2}\right)$, where $m$ and $s$ are the expected value and the standard deviation, respectively.

On the basis of Equation (1), the resultant tensile characteristic $k(u)$ and reliability function $(R)$ of the FBC model can be defined as $(4,5)$ :

$$
\begin{aligned}
& k(u)=\sum_{i=1}^{n} p_{i} k_{i}(u) \\
& R(u)=\sum_{i=1}^{n} p_{i} R_{i}(u)
\end{aligned}
$$

where $\mathrm{k}(u)$ describes the mechanical behaviour without any damage or failure, while $R(u)$ models and characterises the damage process up to ultimate failure.

The FBC modelling method is essentially a decomposition procedure where the components identified from tests characterise the mechanical behaviour of the structural elements of the material tested. 


\section{Experimental}

\section{Producing nonwoven mats by melt blowing}

We prepared nonwoven mats using Borealis HL512FB type PP homopolymer (MFI= $1200 \mathrm{~g} / 10$ $\left.\min 230{ }^{\circ} \mathrm{C} / 2.16 \mathrm{~kg}\right), \mathrm{T}_{\mathrm{m}}=158^{\circ} \mathrm{C}$ ) for hot compaction. The nonwovens were produced with a custom dual-slot melt blowing die, which was attached to a LE8-24C single-screw laboratory mini-extruder (LabTech, Thailand). The die contained 40 fibre-forming capillaries, $330 \mu \mathrm{m}$ diameter each, arranged in a single row. The die and extruder temperature was constant and set to $250{ }^{\circ} \mathrm{C}$. The temperature of the pressurized air $(1.4$ bar $)$ was set to $200{ }^{\circ} \mathrm{C}$ with two $750 \mathrm{~W}$ power inline heaters (AHP-7562, Omega, UK). The die to collector distance (DCD) was set to $150 \mathrm{~mm}$. A drum with a diameter of $160 \mathrm{~mm}$ and rotation speed of $60 \mathrm{rpm}$ was used as the collector, and sample processing time was $10 \mathrm{~min}$. The experimental setup is shown in Figure 2.

Figure 2:The melt blowing experimental setup

\section{Hot compaction processing}

We produced self-reinforced composites by hot compaction with a Polystat 300S type hydraulic hot press (Maschinenfabrik Fr. Schwabenthan \& Gomann, Germany), and laid one nonwoven strip in a U-shape metal mould in every case. The length and width of the mould was $300 \mathrm{~mm}$ and $15 \mathrm{~mm}$, respectively. The samples were compression moulded for $15 \mathrm{~s}$ with a compression pressure of $3 \mathrm{MPa}$ (on the sample). One set of the samples was cold-pressed (in this case, room temperature was $28.8{ }^{\circ} \mathrm{C}$ ), then we produced samples by hot compaction at three different temperatures: $125^{\circ} \mathrm{C}, 135^{\circ} \mathrm{C}$ and $145^{\circ} \mathrm{C}$. The thickness of the hot compacted samples was $0.69 \pm 0.14 \mathrm{~mm}$

\section{Morphology}


The morphology of the fibres was examined by scanning electron microscopy (SEM; Jeol 6380 LA, Japan). We performed SEM on the cryogenic fracture surface of nonwovens and composites. The surface of the samples was finely coated with a gold/palladium alloy with the use of a JEOL JFC-1200 (Jeol Ltd., Japan) fine coater. In case of the nonwoven mat, we measured one hundred individual fibres with the ImageJ $1.51 \mathrm{k}$ software to analyse the fibre diameter distributions.

We analysed the degree of orientation of the PP melt-blown fibre mat by calculating the Herman's orientation factor (f) [38], applying Equations (6) and (7):

$$
\begin{gathered}
f=\frac{3\left\langle\cos ^{2} \phi\right\rangle-1}{2} \\
\left\langle\cos ^{2} \phi\right\rangle=\frac{\sum_{\phi=0^{\circ}}^{90^{\circ}} I(\phi) \cos ^{2} \phi \sin \phi}{\sum_{\phi=0^{\circ}}^{9^{\circ}} I(\phi) \sin \phi}
\end{gathered}
$$

where $\phi$ is the azimuthal angle, $\left\langle\cos ^{2} \phi\right\rangle$ is the weighted expected value of $\cos ^{2} \phi$, and $I(\phi)$ is the grey intensity along the angle $\phi$. If the fibres are randomly orientated, Herman's factor $(f)$ is equal to 0 . If fibres are parallel to a preferred direction (i.e. drawing direction), $f$ equals $1\left(\phi=0^{\circ}\right)$. If fibres are normal to the preferred direction, $f$ equals to $-0.5\left(\phi=90^{\circ}\right)$.

We used the Fast Fourier Transformation method-based approach through the ImageJ software. Three randomly captured SEM images of the nonwoven (PP melt-blown fibre mat) were used for the analysis. The method used transforms the greyscale intensity domain to a frequency spectrum as a function of the spatial variation in pixel intensities.

We used differential scanning calorimetry (DSC) to determine the thermal properties of the samples, carried out with a Q2000 device (TA Instruments, USA). The heat-cool-heat test cycles were performed on 5-10 $\mathrm{mg}$ samples in an inert $\mathrm{N}_{2}$ atmosphere (the flow rate was $50 \mathrm{ml} / \mathrm{min}$ ) with a heating and cooling rate of $10{ }^{\circ} \mathrm{C} / \mathrm{min}$. We determined the degree of crystallinity of the fibres and used $205 \mathrm{~J} / \mathrm{g}$ [39] for the heat of fusion of the $100 \%$ crystalline PP.

\section{Mechanical characterisation \& modelling}


The uniaxial tensile tests were carried out with a Zwick Z005 (Zwick, Germany) universal tensile tester. The precision load cell had a measurement range of $5 \mathrm{kN}$ with a $0.01 \mathrm{~N}$ resolution. 10 tests were performed in every examined case (nonwoven, cold pressed, pressed at $125^{\circ} \mathrm{C}, 135^{\circ} \mathrm{C}$ and $145^{\circ} \mathrm{C}$ ) at a speed of $10 \mathrm{~mm} / \mathrm{min}$. The length and width of the samples were 40 and $15 \mathrm{~mm}$, respectively. The grip distance was $25 \mathrm{~mm}$. The modulus of PP nonwovens and composites was evaluated as the slope of the tensile curves between $0.05 \%$ and $0.25 \%$ strains.

We carried out density measurements with a Sartorius Quintix 125D-1CEU (Sartorius, Germany) semi-micro scale. In the case of the nonwovens and the cold-pressed samples, we measured the weight of the samples and their dimensions and calculated density as mass per unit area. For the composite samples, we used the scale and its associated VF4601 density determination kit operating on the Arrhenius principle. Pure ethanol (Vegyszer Kereskedelmi Kft., Hungary) was used during measurement.

The FBC model was constructed based on the tensile results. We generated a mean tensile curve from the 10 tests (by averaging the data points as a function of strain) for the different specimen types. Then, we used these curves for modelling. Applying Equation (1)-(4), we performed FBC modelling of the total measured stress-strain relationship using Excel. Using iteration, we optimised the model parameters $\left(a_{i}, b_{i}, c_{i}\right.$ and $p_{i}$ of Equation 1-2) to get a minimum relative mean squared error (RMSE) value.

\section{Results and discussion}

\section{SEM of the nonwovens and the composites}

The average fibre diameter of the nonwoven mats was $1.03 \pm 0.8 \mu \mathrm{m}$ and the thickness of the mats was $2.9 \pm 0.2 \mathrm{~mm}$. The SEM micrographs of the nonwovens and composites can be seen in Figure 3. There is no visible difference between the structure of the nonwoven and its cold-pressed counterpart (Figure 3/a vs. 3/b). However, as can be seen later (Figure 4/a), it enhanced tensile 
strength significantly. Cold pressing therefore did not change the morphology of the fibres, but the quality of the bonding among them.

In the case of $125^{\circ} \mathrm{C}$ (Figure $3 / \mathrm{c}$ ), the melting of the fibres took place only to a very small extent, althoufh the micrographs of the $135^{\circ} \mathrm{C}$ and $145^{\circ} \mathrm{C}$ (Figure 3/d and 3/e) samples show a composite that has good consolidation and besides, the fibres and the matrix are clearly distinguishable.

Figure 3: SEM images of the tested samples (a: nonwoven, b: cold-pressed, $c: 125^{\circ} \mathrm{C}, \mathrm{d}: 135^{\circ} \mathrm{C}, e: 145^{\circ} \mathrm{C}$ )

Applying Fast Fourier Transformation conversion from a SEM image to the intensity spectrum (Figure 4), we observed that the nonwoven (PP melt-blown fibre mat) was randomly oriented, and Herman's orientation factor was $0.075 \pm 0.02$. This suggests that the fibre mat had isotropic properties.

Figure 4: SEM image of the nonwoven (PP fibre mat) (a), representative grey intensity spectrum for the Herman's orientation factor calculation (b)

\section{Evaluation of the DSC results and the density measurements}

Figure 5 shows the DSC curves of the materials tested. The summary of the results of the DSC tests and the density measurements can be seen in Table 2 . The density of the bulk PP material was $0.880 \pm 0.002 \mathrm{~g} / \mathrm{cm}^{3}$. The first heating (Figure 5/a) characterises the fibre and the composite structures themselves. There was a slight difference in their degree of crystallinity (Table 2 ). The fibre structure (approx. $1 \mu \mathrm{m}$ diameter) hinders the growth of bigger lamellae via the phase boundaries. Therefore, a higher degree of crystallinity and bigger crystallites can be expected after re-heating. Compression moulding formed a continuous matrix in which there is no such 
constraints of fibre size that increased the crystallinity and besides, it could have acted as thermal annealing.

The second heating (Figure 5/b) rather characterises the material itself (as all the fibres already fused during the first heating) and it confirmed that all the samples behaved similarly upon remelting. Therefore, we can conclude that melt blowing and hot pressing did not alter the PP material significantly and it is possible to recycle these SPC materials easily. At the second heating, a double peak of the PP is visible which implies crystal phase transition [40, 41].

The crystal melting temperature of the fibres and composites, in which the $\alpha$ crystallites dominate, is approximately $5^{\circ} \mathrm{C}$ higher than that of the PP itself.

We tried to increase the compaction temperature further, but at $150{ }^{\circ} \mathrm{C}$, the sample obtained was too brittle and broke while it was removed from the mould. On the other hand, the highest degree of crystallinity was obtained for the sample hot pressed at $135^{\circ} \mathrm{C}$. We found that higher compaction temperature $\left(145^{\circ} \mathrm{C}\right)$ resulted in the fusing of fibres and diminished the fibre content in the composite, and therefore we conclude that $135^{\circ} \mathrm{C}$ gave the best results.

Figure 5: DSC curves of the tested materials (a: 1st cycle, b: 2nd cycle)

Table 2: Characteristic parameters of the tested materials

Table 2 shows that the cold-pressed samples had lower porosity (i.e. higher fibre packing density) and higher density compared to the nonwoven sheet. The degree of crystallinity of the hot compacted composites improved $24 \%$ and $16 \%$ by increasing hot compaction temperature from $125^{\circ} \mathrm{C}$ to $135^{\circ} \mathrm{C}$ and $145^{\circ} \mathrm{C}$, respectively. This indicates inter-fibre adhesion by partially melted fibres. This result is in good agreement with similar findings reported for nonwoven reinforced self-reinforced polymers [24, 26, 42-44]. On the other hand, increasing hot 
compaction temperature resulted in increasing density. The reason for this was decreased polymer viscosity, which led to better consolidation and lower void content.

\section{Evaluation of the tensile tests}

Figure 6 shows the mean curves of the tensile tests and the standard deviations (dashed lines) in every case. Table 3 contains the calculated results. Pictures of the specimens before and after the tensile test can be seen in Figure 7.

Figure 6: Specific force-relative strain curves of the tested materials a: nonwoven and: cold-pressed, b: pressed at $125^{\circ} \mathrm{C}$,

$$
\left.135^{\circ} \mathrm{C} \text {, and } 145^{\circ} \mathrm{C}\right)
$$

\section{Table 3: Calculated results of the tensile tests}

Figure 6 and Table 3 show three different types of curves due to the different compression moulding temperatures. The cold-pressed sample exhibits similar behaviour to the nonwoven mat (Figure 6/a), but the approximately $34-59 \%$ higher specific tensile force values and the lack of initial convex below part at the onset refer to a certain fusion of fibres. The samples pressed at higher temperatures (Figure 6/b) exhibit significantly different behaviour: somewhat higher and a very sharp force peak and an order of magnitude smaller deformation. The rugged curve with gradual damage for $125^{\circ} \mathrm{C}$ becomes smoother for $135^{\circ} \mathrm{C}$ and at $145^{\circ} \mathrm{C}$, it is terminated by catastrophic failure. Hence, increasing the temperature of hot-pressing results in embrittlement (from ductile to brittle) of the samples. The fracture surfaces shown in Figure 6 also confirms this. Increasing hot compaction temperature increases fibre \& matrix bonding (unless the fibres do not melt completely), therefore, it is expected to enhance mechanical behaviours $[20,45,46]$. The specific force maximum of the composites pressed at $135^{\circ} \mathrm{C}$ and $145^{\circ} \mathrm{C}$ is two times greater 
than the specific force maximum of the nonwoven material. These results are consistent with the SEM images and the DSC findings.

Figure 7: Images of the tested samples before (left) and after (right) the tensile test (a: nonwoven, b: cold pressed, $\left.c: 125^{\circ} \mathrm{C}, \mathrm{d}: 135^{\circ} \mathrm{C}, \mathrm{e}: 145^{\circ} \mathrm{C}\right)$

\section{Results of FBC Modelling and Decomposition}

\section{Decomposition of the specific force-relative strain curves}

The tensile curves were averaged in the case of all sample types and these mean curves were used for FBC modelling.

In every case, we chose to use 4 nonlinear E-bundles in the FBC model-based decomposition. We considered the obliqueness of the fibres within the nonwoven with the nonlinearity of the Ebundle. Increasing the number of FBC bundles increases the accuracy of the phenomenological modelling. We found that 4 components gave a fair goodness of fitting (small RMSE and high $\mathrm{R}^{2}$ ) and it kept the model simple and clear.

We characterised the fitting goodness of FBC modelling by calculating the relative mean squared error (RMSE) (related to the measured maximum force value) and the determination coefficient $\left(R^{2}\right)$ between the modelled and measured force data. This fitting goodness is presented in detail for the nonwoven sample in Figure 8. The figure shows the relationship between the measured and modelled forces and linear fitting. 
The detailed graphical results can be seen in Figure 9, including the characteristics of the 4 nonlinear E-bundles obtained, and the model parameters are summarized in Table 4. The table also includes this goodness of fitting for all the specimen types.

If parameter $a$ of the FBC curve shown in Table 4 is negative, then the initial part of the FBC curve is convex below, and this indicates that the fibres were wavy in the grip. If $a=0$, a linear tensile characteristic is obtained, and if $a$ is positive, the initial slope will be larger, and the initial part of the FBC curve is concave below. $b$ controls the curvature of the initial part of the curve and $c$ is the asymptotic tensile stiffness.

High goodness of modelling is indicated by the facts that the determination coefficients are larger than 0.99 and the RMSE values are smaller than $3 \%$.

Figure 9: The E-bundle components of the FBC model curve in every case (a: nonwoven, b: cold-pressed, c: $125{ }^{\circ} \mathrm{C}$,

$$
\left.d: 135^{\circ} \mathrm{C}, e: 145^{\circ} \mathrm{C}\right)
$$

Table 4: The FBC model parameters in the modelled cases

\section{Model tensile characteristics}

Besides characterizing the intact functioning, the weighted sum of the tensile characteristics (Equation 4) of the four E-bundles reflect the resultant hardening or stiffening as a result of pressing and heating (Figure 10). These tensile characteristics are multiplied by the weighted reliability functions (Equation 5) to give the tensile curves (Equation 1). We can see the big differences between the tensile stiffness of the different samples from the tensile characteristics. 
The nonwovens show a greatly nonlinear characteristics and one order of magnitude lower values at the same strains. The composites are closer to the ideally linear characteristics.

Figure 10: The initial parts of the tensile characteristics of the examined samples

\section{Reliability functions}

The reliability function belonging to a load mode should be a very important characteristic in designing engineering constructions. The FBC model makes it possible not only to determine the resultant reliability function (Figure 11), but to assess its components as well. In the examined cases, the reliability function shows the proportion of fibres that are still intact. In the case of the nonwoven mat and the cold-pressed sample, failure is a relatively slow process, while in the case of composites, it is a sudden event. At $145{ }^{\circ} \mathrm{C}$, drastic, catastrophic failure can be observed. These reliability functions in the model are closely related to and in good agreement with the tensile test results.

Figure 11: The reliability functions of the examined samples

\section{E-bundle components}

Using two different magnifications, Figure 12 compares the individual model components denoted by the same number. Disregarding some smaller deviations, they are similar for the nonwoven and cold-pressed mats and the composites. Components 1 and 2 characterise the ascending part of the measured mean force-strain curve, while component 4 characterises the 
descending part. Component 3 plays a role in the middle section. Component 4 has smaller significance, except for the composite pressed at $145^{\circ} \mathrm{C}$.

Figure 12: The individual model components denoted by the same serial number (a: component no.1, b: component no.2, c:

component no.3, d: component no.4)

\section{The advantages of the FBC modelling method}

The presented FBC model is a novel and simple method to describe not only the deformation of the nonwovens, but also their failure process (after the stress peak).

In general, the stress-strain curve, recorded during a tensile test performed up to the general failure or the fracture of the sample, represents a stochastic process containing a deformation and a failure process. The stress-strain curve is the measured response of the sample to a constant rate extension. The initial part of this curve belongs to a pure deformation process without any damage, while the other part including the possible peak is the result of the increasing deformation modified by the effects of the local stochastic damage and failures within the fibrous structure. The total deformation and failure process can be described by a FBC model that is, in this special case, a series of parallel connected nonlinear E-bundles where every local damage or failure is modelled by the breakage of a suitable model fibre. The expected value of the tensile stress or force as the response of the FBC model is calculated and fitted to the measured stressstrain curve. The model fibres belonging to a series of similar local damage or failure create a nonlinear E-bundle. The fraction (weight) and strength properties of the different E-bundles can be determined by decomposing the fitted tensile stress or force process. In the knowledge of these components for both the nonwoven and the composite samples, the similarities and differences can be analysed. In the model, the expected damage and failure process is taken into account with the reliability function, which is a very important characteristic for designing 
engineering constructions. FBC modelling can be applied to describe the expected total deformation and failure process of not only fibrous materials such as textiles, mats and fibre reinforced composites but polymers as well.

The modelling requires a small computing capacity, hence it is a fast and cheap process, compared to FEM analysis or Monte Carlo simulations. Moreover, the model is based on real measurements, which were carried out on real materials, but on the other hand it uses probability values that makes the calculations simple and fast.

\section{Conclusions}

We successfully produced single PP composites made from melt-blown nonwovens with an average diameter of $1.03 \mu \mathrm{m}$ using hot-compaction at different temperatures. Then we compared the structural-mechanical properties of the composites produced to the original melt-blown nonwoven and the cold-pressed nonwoven material.

The tensile tests of the nonwovens and composites revealed that increasing the temperature of hot-pressing results in embrittlement (from ductile to brittle) of the samples, which means higher specific tensile forces and smaller deformations. The cold-pressed sample exhibits similar behaviour to the nonwoven mat, but the approximately $46.5 \pm 12.5 \%$ higher specific tensile force and the lack of initial convex below part at the onset refer to a certain fusion of fibres. The specific force maximums of the composites pressed at $135{ }^{\circ} \mathrm{C}$ and $145{ }^{\circ} \mathrm{C}$ were $109 \pm 29 \%$ and $107 \pm 28 \%$ greater than the specific force maximum of the nonwoven material, respectively.

SEM analysis revealed that we were able to maintain a decent amount of fibres even at the temperature of compression and a continuous matrix formed around them. The composite had good consolidation, low void content and besides, the fibres and the matrix were clearly distinguishable. 
The DSC tests showed that the composites are easy to recycle by re-melting. Besides, hot compaction increased the degree of crystallinity. In the case of the samples pressed at $135^{\circ} \mathrm{C}$ and $145^{\circ} \mathrm{C}$, the increment (compared to the nonwoven sample) was $9 \%$ and $17 \%$, respectively.

Using the Fibre Bundle Cells modelling method, we developed a phenomenological, analytical model to describe the entire tensile curve (both the deformation and the failure behaviour) of the nonwovens and the composites. High goodness of modelling was indicated by the facts that the determination coefficients $\left(R^{2}\right)$ between the modelled and measured force were larger than 0.99 and the relative mean squared error ( $R M S E)$ (related to the measured maximum force value) was smaller than $3 \%$ in every examined case. That means that the FBC model can not only be used to describe the tensile behaviour of the nonwovens, but it was also applicable for the composites as well. The modelling requires a small computing capacity, hence it is a fast and cheap process, compared to FEM analysis or Monte Carlo simulations.

\section{Acknowledgements}

This research was supported by the National Research, Development and Innovation Office (OTKA 116189) and by the ÚNKP-19-3 and the ÚNKP-20-5 New National Excellence Program of the Ministry for Innovation and Technology.

This paper was also supported by the János Bolyai Research Scholarship of the Hungarian Academy of Sciences. The research reported in this paper and carried out at BME has been supported by the NRDI Fund (TKP2020 NC,Grant No. BME-NC) based on the charter of bolster issued by the NRDI Office under the auspices of the Ministry for Innovation and Technology.

\section{References}

1. D. Bhattacharyya, Express Polymer Letters - EXPRESS POLYM LETT, 3, 525 (2009). 
2. K. Matabola, A. R. Vries, A. Luyt, and R. Kumar, eXPRESS Polymer Letters, 5, 635 (2011).

3. K. Bocz, A. Toldy, Á. Kmetty, T. Bárány, T. Igricz, and G. Marosi, Polymer degradation and stability, 97, 221 (2012).

4. J. Chen, C. Wu, F. Pu, and C. Chiu, Express Polymer Letters, 5 (2011).

5. $\quad$ N. J. Capiati and R. S. Porter, Journal of materials science, 10, 1671 (1975).

6. G. Romhany, T. Barany, T. Czigany, and J. Karger-Kocsis, Polymers for Advanced Technologies, 18, 90 (2007).

7. Á. Kmetty, T. Bárány, and J. Karger-Kocsis, Progress in Polymer Science, 35, 1288 $(2010)$

8. K. Matabola, A. Vries, F. Moolman, and A. Luyt, Journal of Materials Science, 44, 6213 (2009).

9. W. H. Gazzola, R. S. Benson, and W. Carver, Annals of Plastic Surgery, 83, 716 (2019).

10. A. Brochocka, A. Nowak, K. Majchrzycka, M. Puchalski, and S. Sztajnowski, Materials, 13, $712(2020)$.

11. F. Sun, T.-T. Li, X. Zhang, B.-C. Shiu, Y. Zhang, H.-T. Ren, H.-K. Peng, J.-H. Lin, and C.-W. Lou, Chemosphere, 126873 (2020).

12. J. Gao, J. Luo, L. Wang, X. Huang, H. Wang, X. Song, M. Hu, L.-C. Tang, and H. Xue, Chemical Engineering Journal, 364, 493 (2019).

13. X. Tang, X. Zhang, X. Zhuang, H. Zhang, and X. Yan, Polymer Composites, 40, 2012 (2019).

14. D. Vadas, D. Kmetykó, G. Marosi, and K. Bocz, Polymers, 10, 766 (2018).

15. A. Nickel and N. Jording, "Tempered Melt-Blown Nonwoven Having a High Compression Hardness", USA, 2020.

16. I. Ward and P. Hine, Polymer Engineering \& Science, 37, 1809 (1997). 
17. I. M. Ward and P. J. Hine, Polymer, 45, 1413 (2004).

18. T. Barany, Express Polymer Letters, 14, 400 (2020).

19. G. Talarico, C. De Rosa, and F. Auriemma, in "Polypropylene Handbook: Morphology, Blends and Composites" (J. Karger-Kocsis and T. Bárány, Eds.), pp. 1, Springer International Publishing, Cham, 2019.

20. Y.-T. Hwang, S.-Y. Kang, D.-H. Kim, and H.-S. Kim, Composite Structures, 210, 767 (2019).

21. M. I. Abo El-Maaty, D. C. Bassett, R. H. Olley, P. J. Hine, and I. M. Ward, Journal of Materials Science, 31, 1157 (1996).

22. P. J. Hine, I. M. Ward, N. D. Jordan, R. Olley, and D. C. Bassett, Polymer, 44, 1117 (2003).

23. N. D. Jordan, D. C. Bassett, R. H. Olley, P. J. Hine, and I. M. Ward, Polymer, 44, 1133 (2003).

24. J. L. Mijares, E. Agaliotis, C. R. Bernal, and M. Mollo, Polymers for Advanced Technologies, 29, 111 (2018).

25. D. Vadas, D. Kmetykó, G. Marosi, and K. Bocz, Polymers, 10, 766 (2018).

26. K. Somord, O. Suwantong, N. Tawichai, T. Peijs, and N. Soykeabkaew, Polymer, 103, $347(2016)$

27. F. Zuo, D. H. Tan, Z. Wang, S. Jeung, C. W. Macosko, and F. S. Bates, ACS Macro Letters, 2, 301 (2013).

28. R. Nayak, R. Padhye, L. Arnold, I. L. Kyratzis, Y. B. Truong, G. Peeters, L. Nichols, and M. O'Shea, Applied Mechanics and Materials, 217-219, 207 (2012).

29. M. Guo, H. Liang, Z. Luo, Q. Chen, and W. Wei, Fibres and Polymers, 17, 257 (2016).

30. K. Matabola, A. de Vries, A. Luyt, and R. Kumar, eXPRESS Polymer Letters, 5, 635 (2011) 
31. A. Szekrényes and J. Uj, Periodica Polytechnica Mechanical Engineering, 46, 139 (2002).

32. L. Vas, Z. Kocsis, T. Czigány, P. Tamás, and G. Romhány, Journal of Composite Materials, 002199831982666 (2019).

33. L. M. Vas, Journal of Composite Materials, 40, 1695 (2006).

34. L. M. Vas, "Idealised statistical fibre bundle cells and their application to modelling fibrous structures, composites (in Hungarian)", Budapest, 2007.

35. L. M. Vas and Z. Rácz, Journal of Composite Materials, 38, 1757 (2004).

36. L. M. Vas, Z. Rácz, and P. Nagy, Journal of Composite Materials, 38, 1787 (2004).

37. L. M. Vas and P. Tamás, Plastics, Rubber and Composites, 37, 233 (2008).

38. H. Zhang, H. Bai, S. Deng, Z. Liu, Q. Zhang, and Q. Fu, Polymer, 166, 13 (2019).

39. G. R. G. W. Ehrenstein, P. Trawiel, "Praxis der Thermischen Analyse von Kunststoffen", Carl Hanser Verlag, München, Germany, 2003.

40. J. Daenicke, M. Lämmlein, F. Steinhübl, and W. Schubert Dirk, "Revealing key parameters to minimize the diameter of polypropylene fibres produced in the melt electrospinning process", 2019.

41. R. Nayak, I. L. Kyratzis, Y. B. Truong, R. Padhye, L. Arnold, G. Peeters, M. O’Shea, and L. Nichols, Journal of Materials Science, 48, 273 (2012).

42. R. Shanks and I. Mustapa, "All-poly(lactic acid) composites prepared by compression moulding of non-woven precursors", 2011.

43. Y. V. Vazquez, L. A. Castillo, and S. E. Barbosa, Polymer Composites, 41, 1962 (2020).

44. Q. Liu, M. Zhao, Y. Zhou, Q. Yang, Y. Shen, R. H. Gong, F. Zhou, Y. Li, and B. Deng, Materials \& Design, 139, 36 (2018).

45. T. Bárány, J. Karger-Kocsis, and T. Czigány, Polymers for Advanced Technologies, 17, $818(2006)$ 
46. P. J. Hine, A. Astruc, and I. M. Ward, Journal of Applied Polymer Science, 93, 796 (2004). 

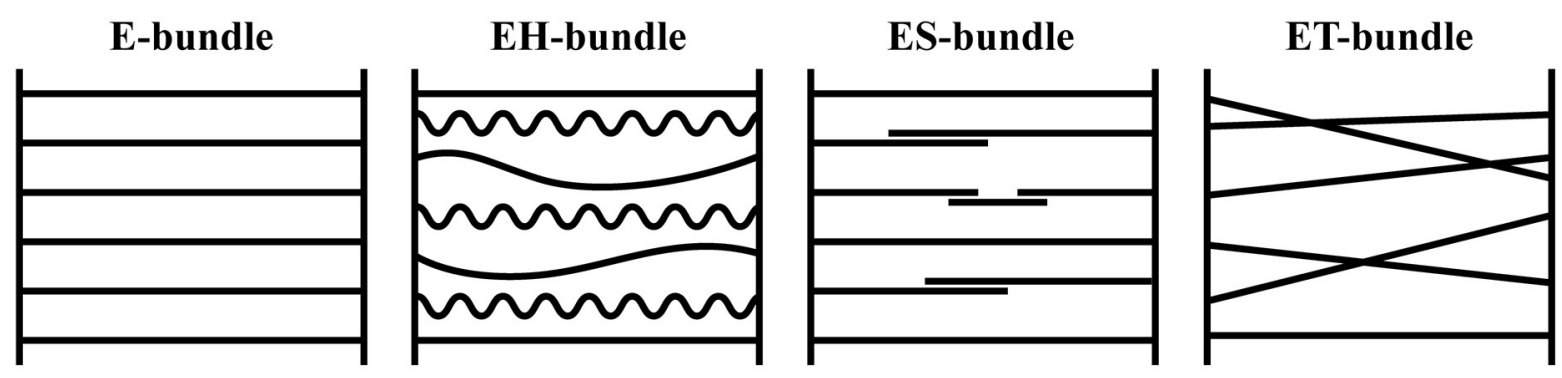

Figure 1: The schematics of the base bundles [34]

\begin{tabular}{|c|c|c|c|c|}
\hline $\begin{array}{c}\text { Name of } \\
\text { basic bundle }\end{array}$ & E-bundle & EH-bundle & ES-bundle & ET-bundle \\
\hline $\begin{array}{l}\text { Mechanical } \\
\text { state of } \\
\text { fibres }\end{array}$ & $\begin{array}{c}\text { ideal } \\
\text { (fibres are perfectly } \\
\text { flexible, linearly } \\
\text { elastic, and not pre- } \\
\text { strained) }\end{array}$ & $\frac{\text { fibres may be }}{\text { pre-strained }}$ & ideal & ideal \\
\hline $\begin{array}{l}\text { Geometrical } \\
\text { position of } \\
\text { fibres }\end{array}$ & $\begin{array}{l}\text { ideal } \\
\text { (fibres are straight, } \\
\text { independent of one } \\
\text { another, parallel to } \\
\text { one another and the } \\
\text { direction of } \\
\text { straining) }\end{array}$ & $\frac{\text { fibres may be }}{\underline{\text { crimped }}}$ & ideal & $\frac{\text { fibres may be }}{\text { oblique }}$ \\
\hline $\begin{array}{l}\text { Gripping of } \\
\text { fibres }\end{array}$ & $\begin{array}{l}\text { ideal } \\
\text { (fibres are gripped } \\
\text { at both ends, not } \\
\text { pre-strained, do not } \\
\text { slip out of the grips } \\
\text { and do not break in } \\
\text { the grips) }\end{array}$ & ideal & $\begin{array}{l}\text { fibres can slip out } \\
\text { of the grips or they } \\
\frac{\text { can create fibre }}{\text { chains with }} \\
\text { slipping bonds) }\end{array}$ & ideal \\
\hline
\end{tabular}

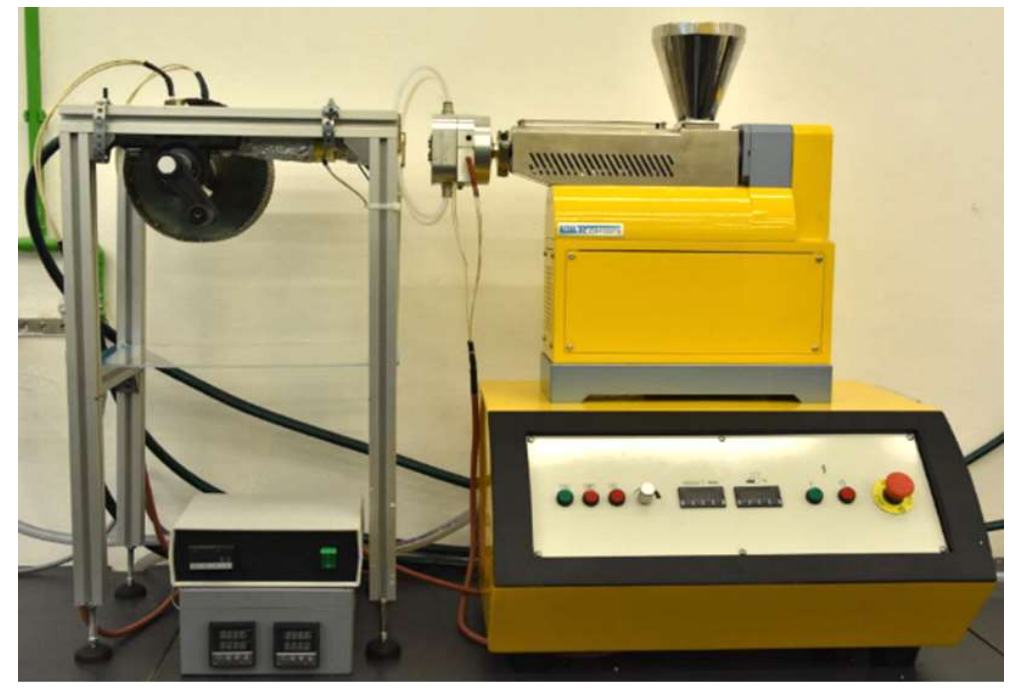

Figure 2: The melt blowing experimental setup 


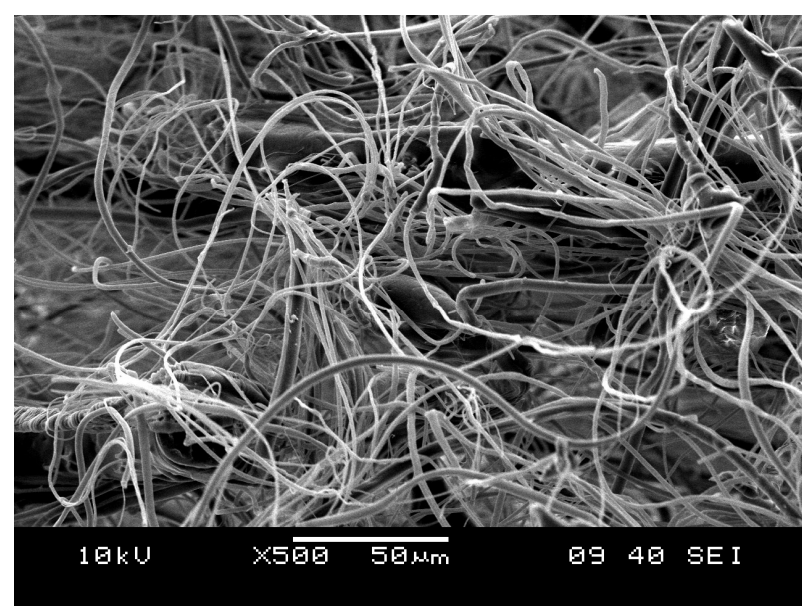

a)

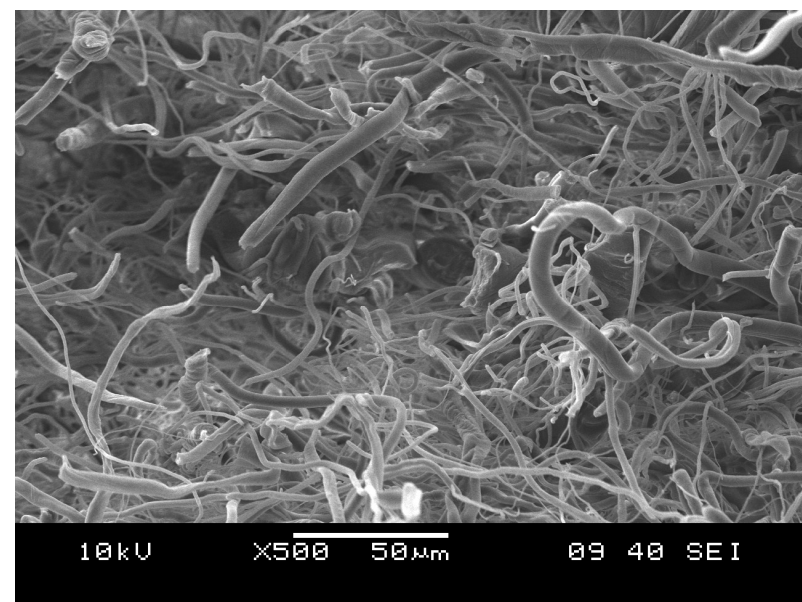

c)

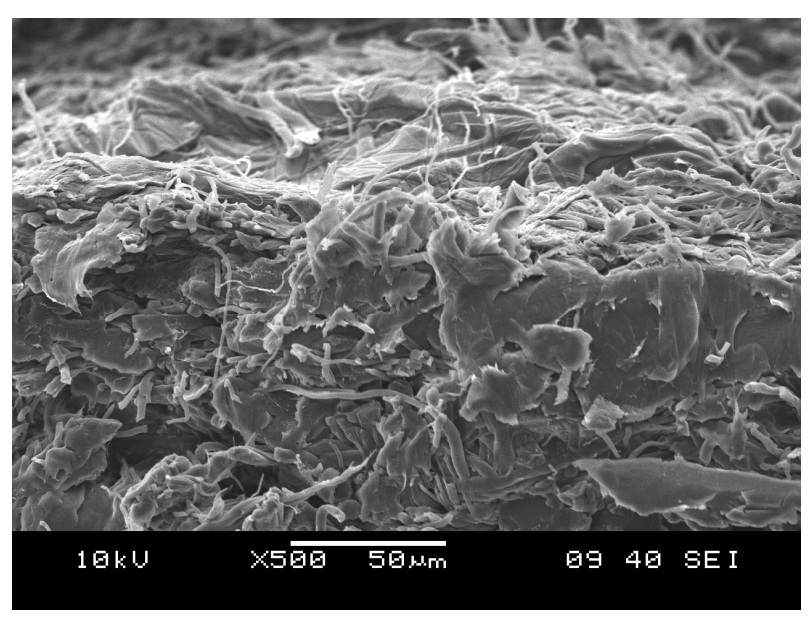

e)

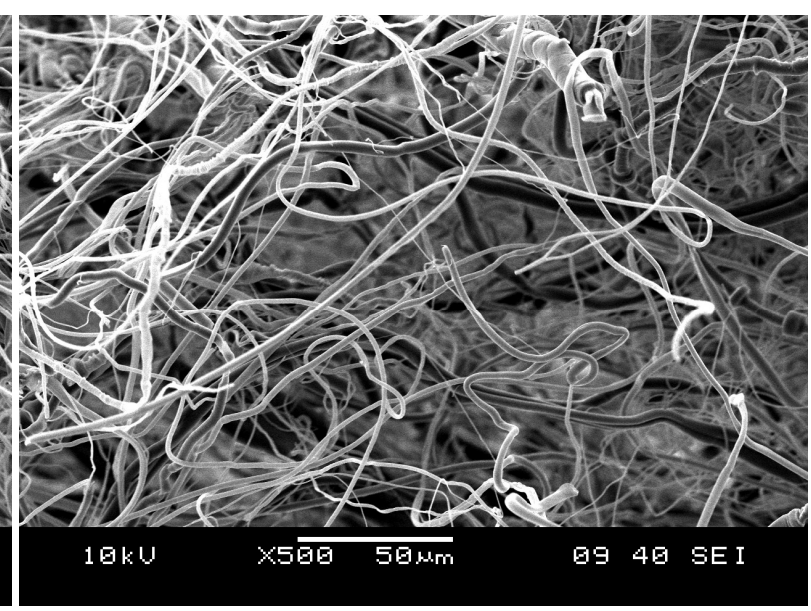

b)

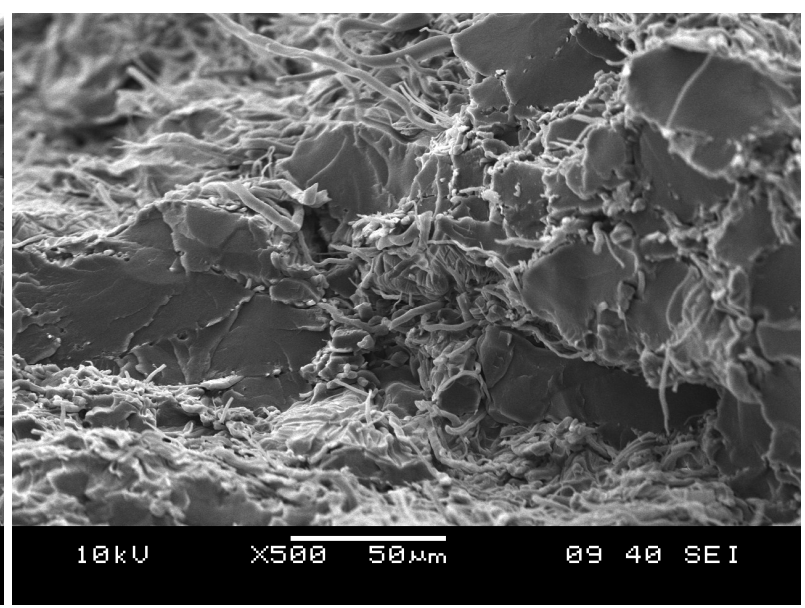

d) 


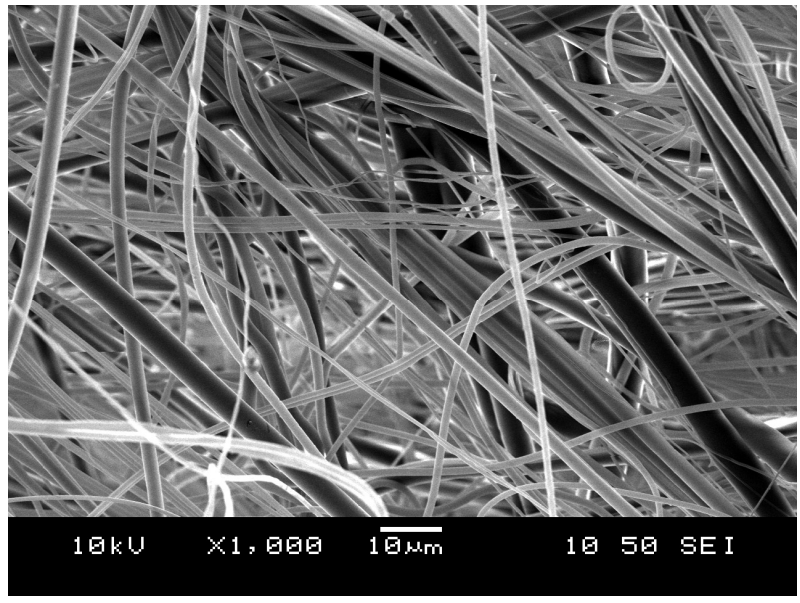

a)

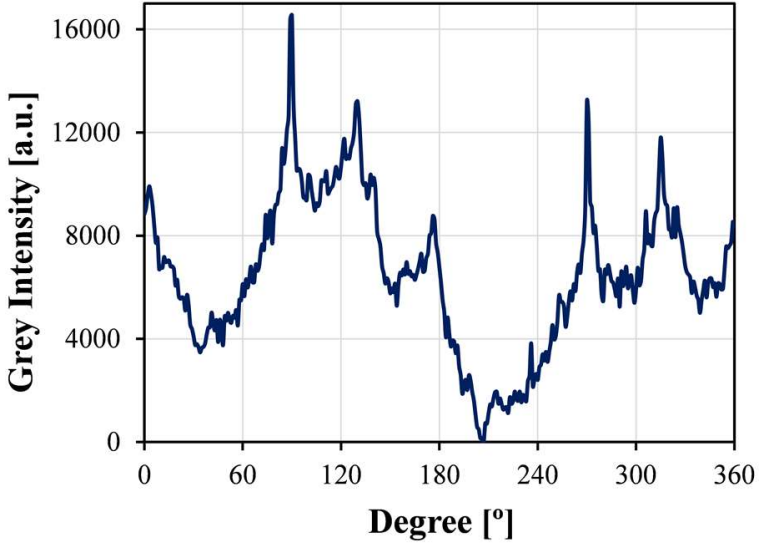

b)

Figure 4: SEM image of the nonwoven (PP fibre mat) (a), representative grey intensity spectrum for the Herman's orientation factor calculation (b)

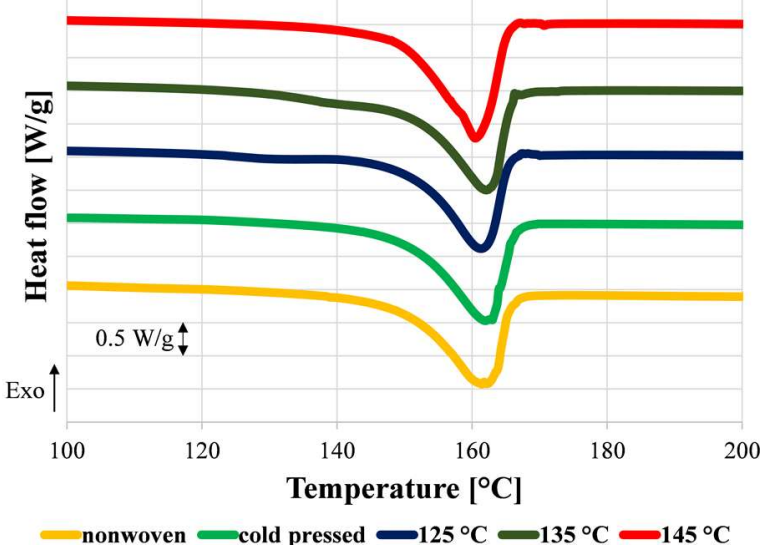

a)

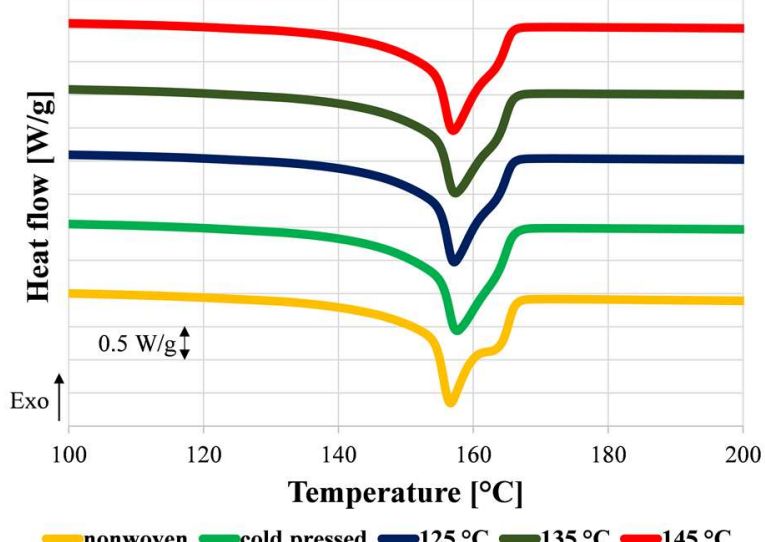

b)

Figure 5: DSC curves of the tested materials (a: 1st cycle, b: 2nd cycle)

\begin{tabular}{|c|c|c|c|c|c|c|}
\hline & \multicolumn{2}{|c|}{ First heating } & \multicolumn{2}{|c|}{ Second heating } & \multirow[b]{2}{*}{$\begin{array}{l}\text { Density } \\
{\left[\mathrm{g} / \mathrm{cm}^{3}\right]}\end{array}$} & \multirow[b]{2}{*}{$\begin{array}{c}\text { Porosity } \\
{[\%]}\end{array}$} \\
\hline & $\begin{array}{c}\text { Degree of } \\
\text { crystallinity } \\
{[\%]}\end{array}$ & $\begin{array}{c}\text { Melting } \\
\text { temperature } \\
{\left[{ }^{\circ} \mathbf{C}\right]}\end{array}$ & $\begin{array}{c}\text { Degree of } \\
\text { crystallinity } \\
{[\%]}\end{array}$ & $\begin{array}{c}\text { Melting } \\
\text { temperature } \\
\left(1^{\text {st }} \text { peak }\right)\left[{ }^{\circ} \mathrm{C}\right]\end{array}$ & & \\
\hline nonwoven & 54 & 161.5 & 54 & 156.6 & $0.16 \pm 0.020$ & $81.7 \pm 0.4$ \\
\hline cold pressed & 55 & 161.9 & 58 & 157.6 & $0.18 \pm 0.009$ & $79.4 \pm 1.1$ \\
\hline $125^{\circ} \mathrm{C}$ & 51 & 161.3 & 54 & 157.2 & $0.866 \pm 0.018$ & - \\
\hline $135^{\circ} \mathrm{C}$ & 63 & 162.1 & 56 & 157.3 & $0.884 \pm 0.007$ & - \\
\hline $145^{\circ} \mathrm{C}$ & 59 & 160.5 & 54 & 157.0 & $0.883 \pm 0.005$ & - \\
\hline
\end{tabular}

Table 2: Characteristic parameters of the tested materials 


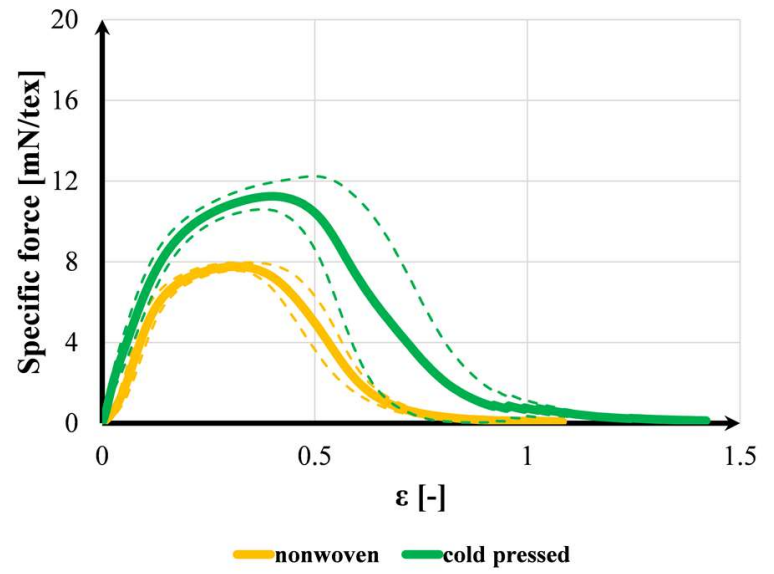

a)

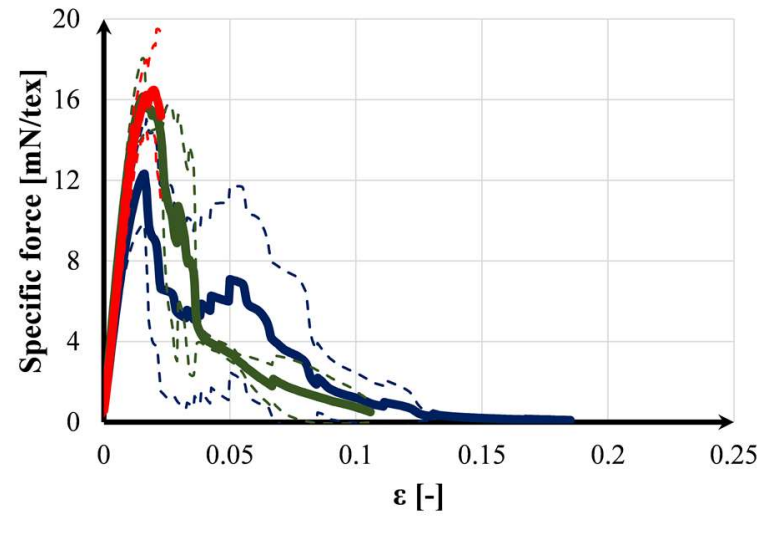

$-125^{\circ} \mathrm{C}=135^{\circ} \mathrm{C}=145^{\circ} \mathrm{C}$

b)

Figure 6: Specific force-relative strain curves of the tested materials a: nonwoven and cold pressed, b: pressed at $125{ }^{\circ} \mathrm{C}$, $135^{\circ} \mathrm{C}$, and $145^{\circ} \mathrm{C}$ )

\begin{tabular}{cccc}
\hline & $\begin{array}{c}\text { Specific } \\
\text { force } \\
\text { maximum } \\
{[\mathbf{m N} / \text { tex }]}\end{array}$ & $\begin{array}{c}\text { Elongation at } \\
\text { maximum } \\
\text { specific force } \\
{[-]}\end{array}$ & $\begin{array}{c}\text { Specific } \\
\text { tensile } \\
\text { stiffness } \\
{[\mathbf{m N} / \text { tex }]}\end{array}$ \\
\hline $\begin{array}{c}\text { nonwoven } \\
\text { cold } \\
\text { pressed }\end{array}$ & $7.83 \pm 0.23$ & $1.007 \pm 0.082$ & $19.3 \pm 9.15$ \\
$\mathbf{1 2 5}^{\circ} \mathbf{C}$ & $11.41 \pm 0.72$ & $1.182 \pm 0.234$ & $54.6 \pm 17.6$ \\
$\mathbf{1 3 5}^{\circ} \mathbf{C}$ & $12.88 \pm 2.37$ & $0.088 \pm 0.058$ & $1041 \pm 125$ \\
$\mathbf{1 4 5}^{\circ} \mathbf{C}$ & $16.14 \pm 1.70$ & $0.047 \pm 0.047$ & $1374 \pm 226$ \\
\hline \multicolumn{4}{c}{ Table 3: Calculated results of the tensile tests }
\end{tabular}




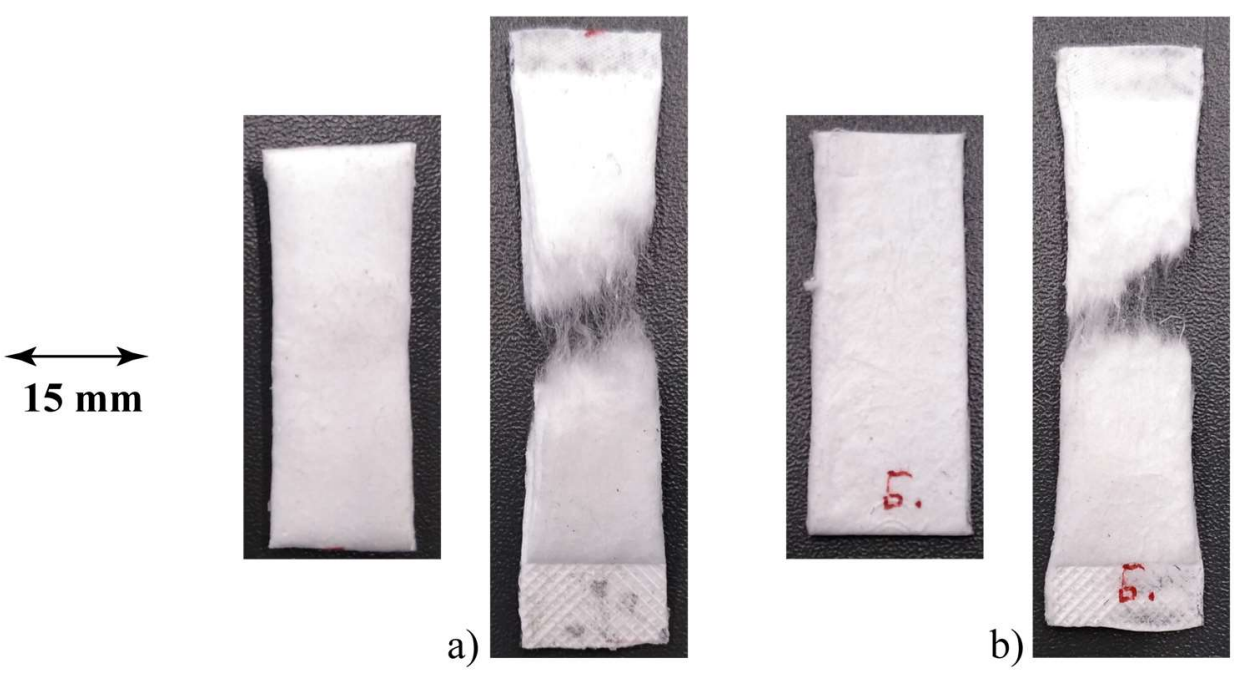

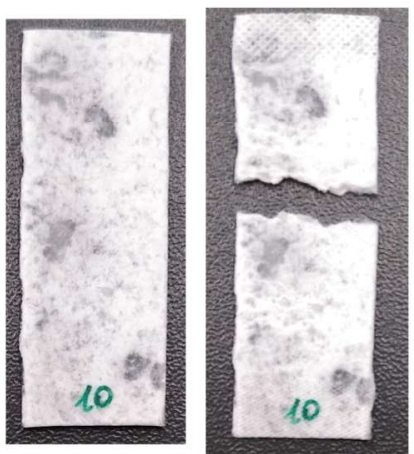

c)

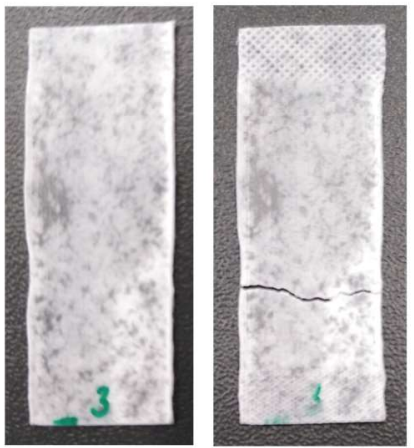

d)

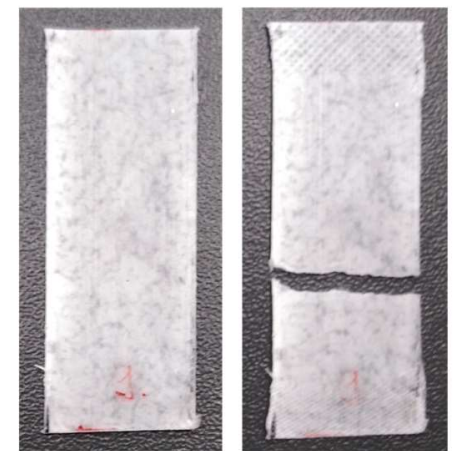

e)

Figure 7: Pictures of the tested samples before (left) and after (right) the tensile test (a: nonwoven, b: cold pressed, $c: 125^{\circ} \mathrm{C}, \mathrm{d}: 135^{\circ} \mathrm{C}, \mathrm{e}: 145^{\circ} \mathrm{C}$ )

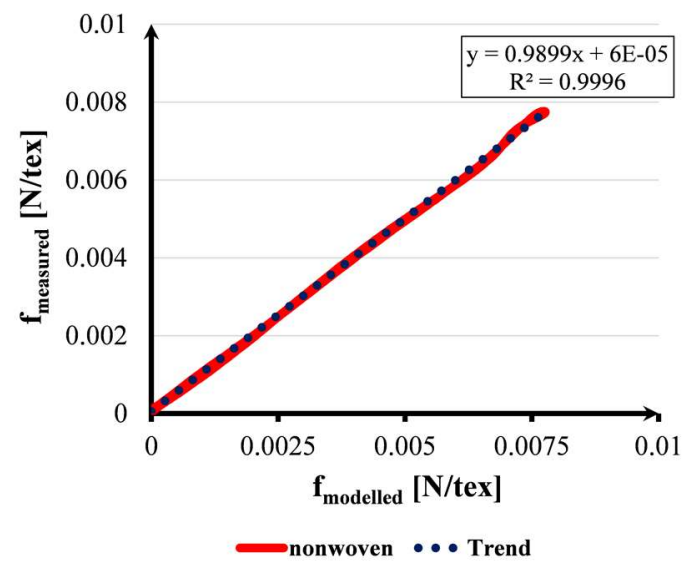

Figure 8: The goodness of the fitting of nonwoven samples 


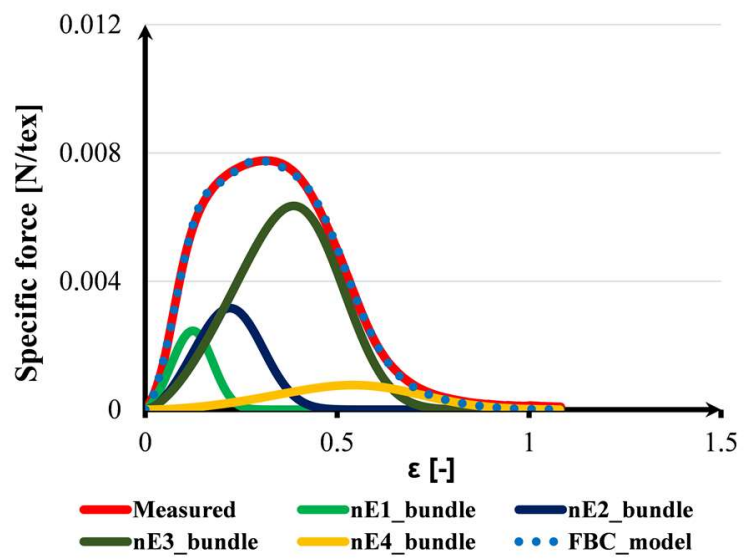

a)

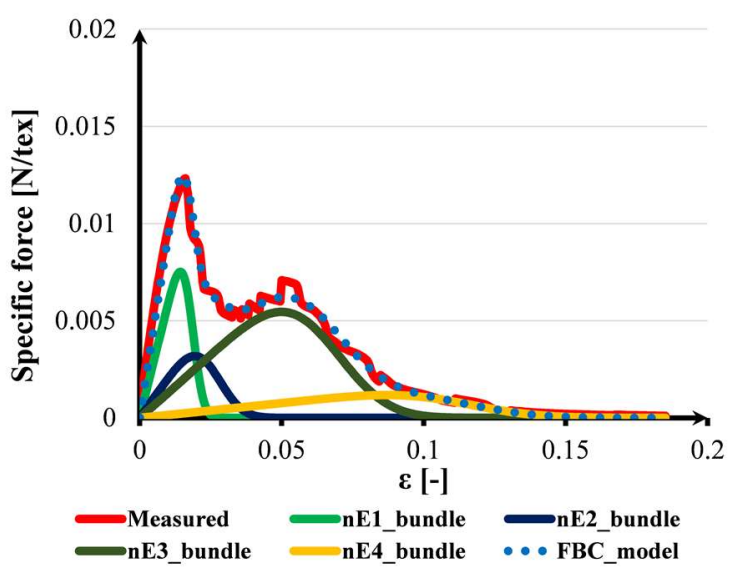

c)

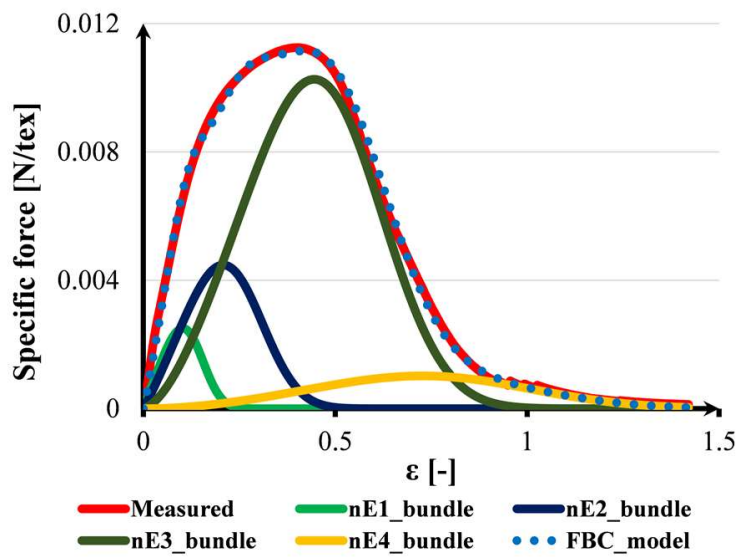

b)

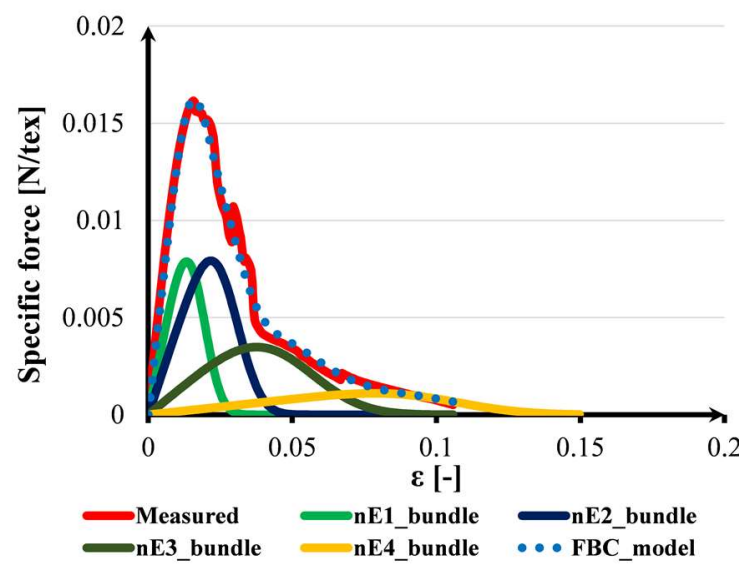

d)

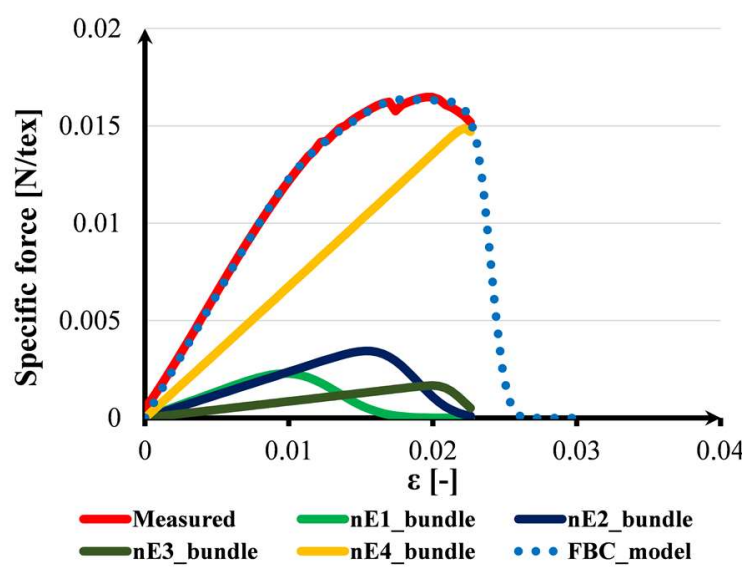

e)

Figure 9: The E-bundle components of the FBC model-curve in every case (a: nonwoven, b: cold pressed, $c: 125^{\circ} \mathrm{C}$, $d: 135^{\circ} \mathrm{C}, \mathrm{e}: 145^{\circ} \mathrm{C}$ ) 


\begin{tabular}{|c|c|c|c|c|c|c|}
\hline Case & Parameters & $\mathrm{nE}_{1}$ & $\mathrm{nE}_{2}$ & $\mathbf{n E}_{3}$ & $\mathrm{nE}_{4}$ & FBC \\
\hline \multirow{9}{*}{ Nonwoven } & $p[-]$ & 0.3 & 0.3 & 0.3 & 0.1 & 1.0 \\
\hline & $\boldsymbol{a}[\mathrm{N} / \mathrm{tex}]$ & -0.013 & -0.013 & -0.013 & -0.025 & -0.014 \\
\hline & $\boldsymbol{b}[-]$ & 12 & 9 & 7 & 2 & 8.6 \\
\hline & $c[\mathrm{~N} / \mathrm{tex}]$ & 0.18 & 0.12 & 0.1 & 0.05 & 0.125 \\
\hline & $\boldsymbol{m}[-]$ & 0.144 & 0.258 & 0.47 & 0.63 & 0.325 \\
\hline & $\boldsymbol{s}[-]$ & 0.046 & 0.075 & 0.1 & 0.147 & 0.087 \\
\hline & $c \boldsymbol{C}=c+a \cdot b$ & 0.024 & 0.003 & 0.009 & 0 & 0.011 \\
\hline & $R M S E$ [\%] & & & & & 0.91 \\
\hline & $R^{2}$ & & & & & 0.9996 \\
\hline \multirow{9}{*}{ Cold pressed } & $p[-]$ & 0.18 & 0.3 & 0.43 & 0.09 & 1.0 \\
\hline & $\boldsymbol{a}[\mathrm{N} / \mathrm{tex}]$ & 0 & -0.005 & -0.013 & -0.025 & -0.009 \\
\hline & $\boldsymbol{b}[-]$ & 12 & 9 & 7 & 2 & 8.050 \\
\hline & $c[\mathrm{~N} / \mathrm{tex}]$ & 0.18 & 0.12 & 0.1 & 0.05 & 0.116 \\
\hline & $\boldsymbol{m}[-]$ & 0.132 & 0.258 & 0.54 & 0.83 & 0.408 \\
\hline & $s[-]$ & 0.043 & 0.086 & 0.145 & 0.25 & 0.131 \\
\hline & $c \boldsymbol{\theta}=c+a \cdot b$ & 0.18 & 0.075 & 0.009 & 0 & 0.059 \\
\hline & $\operatorname{RMSE}[\%]$ & & & & & 1.84 \\
\hline & $R^{2}$ & & & & & 0.9983 \\
\hline \multirow{9}{*}{$125^{\circ} \mathrm{C}$} & $p[-]$ & 0.28 & 0.3 & 0.32 & 0.1 & 1.0 \\
\hline & $\boldsymbol{a}[\mathrm{N} / \mathrm{tex}]$ & 0.0006 & -0.013 & -0.013 & -0.025 & -0.010 \\
\hline & $\boldsymbol{b}[-]$ & 12 & 9 & 7 & 2 & 8.500 \\
\hline & $c[\mathrm{~N} /$ tex $]$ & 2.1 & 0.8 & 0.49 & 0.2 & 1.005 \\
\hline & $\boldsymbol{m}[-]$ & 0.018 & 0.025 & 0.064 & 0.11 & 0.044 \\
\hline & $s[-]$ & 0.003 & 0.007 & 0.015 & 0.02 & 0.011 \\
\hline & $c 0=c+a \cdot b$ & 2.1072 & 0.683 & 0.399 & 0.15 & 0.938 \\
\hline & $R M S E[\%]$ & & & & & 2.64 \\
\hline & $R^{2}$ & & & & & 0.9902 \\
\hline \multirow{9}{*}{$135^{\circ} \mathrm{C}$} & $p[-]$ & 0.27 & 0.31 & 0.32 & 0.1 & 1.0 \\
\hline & $a[\mathrm{~N} / \mathrm{tex}]$ & 0.0006 & -0.013 & -0.013 & -0.025 & -0.011 \\
\hline & $\boldsymbol{b}[-]$ & 12 & 9 & 7 & 2 & 8.470 \\
\hline & $c[\mathrm{~N} / \mathrm{tex}]$ & 2.8 & 1.55 & 0.47 & 0.21 & 1.408 \\
\hline & $\boldsymbol{m}[-]$ & 0.0172 & 0.028 & 0.048 & 0.1 & 0.039 \\
\hline & $s[-]$ & 0.005 & 0.007 & 0.016 & 0.02 & 0.012 \\
\hline & $c 0=c+a \cdot b$ & 2.8072 & 1.433 & 0.379 & 0.16 & 1.339 \\
\hline & $\operatorname{RMSE}$ [\%] & & & & & 2.93 \\
\hline & $R^{2}$ & & & & & 0.9906 \\
\hline \multirow{9}{*}{$145^{\circ} \mathrm{C}$} & $p[-]$ & 0.18 & 0.24 & 0.1 & 0.48 & 1.0 \\
\hline & $a[\mathrm{~N} / \mathrm{tex}]$ & 0.0006 & -0.013 & -0.025 & -0.013 & -0.012 \\
\hline & $\boldsymbol{b}[-]$ & 12 & 9 & 2 & 9 & 8.840 \\
\hline & $c[\mathrm{~N} / \mathrm{tex}]$ & 1.5 & 1.1 & 0.9 & 1.52 & 1.354 \\
\hline & $\boldsymbol{m}[-]$ & 0.0125 & 0.0185 & 0.022 & 0.024 & 0.020 \\
\hline & $s[-]$ & 0.0025 & 0.002 & 0.001 & 0.0008 & 0.002 \\
\hline & $\boldsymbol{c} \boldsymbol{0}=\boldsymbol{c}+\boldsymbol{a} \cdot \boldsymbol{b}$ & 1.5072 & 1.009 & 0.85 & 1.403 & 1.272 \\
\hline & $\operatorname{RMSE}[\%]$ & & & & & 1.21 \\
\hline & $R^{2}$ & & & & & 0.9993 \\
\hline
\end{tabular}

Table 4: The FBC model parameters in the modelled cases 

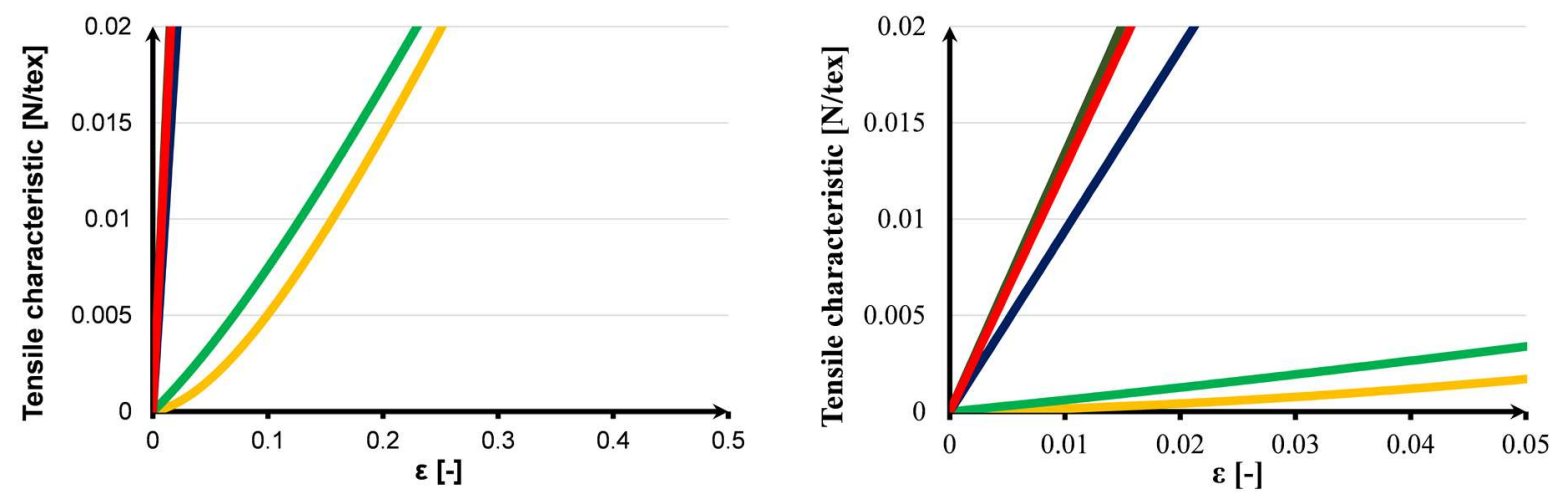

nonwoven $=$ cold pressed $\longrightarrow 125^{\circ} \mathrm{C} \longrightarrow 135^{\circ} \mathrm{C}=145^{\circ} \mathrm{C}$

nonwoven $=$ cold pressed $\longrightarrow 125^{\circ} \mathrm{C} \longrightarrow 135^{\circ} \mathrm{C} \longrightarrow 145^{\circ} \mathrm{C}$

Figure 10: The initial parts of the tensile characteristics of the examined samples
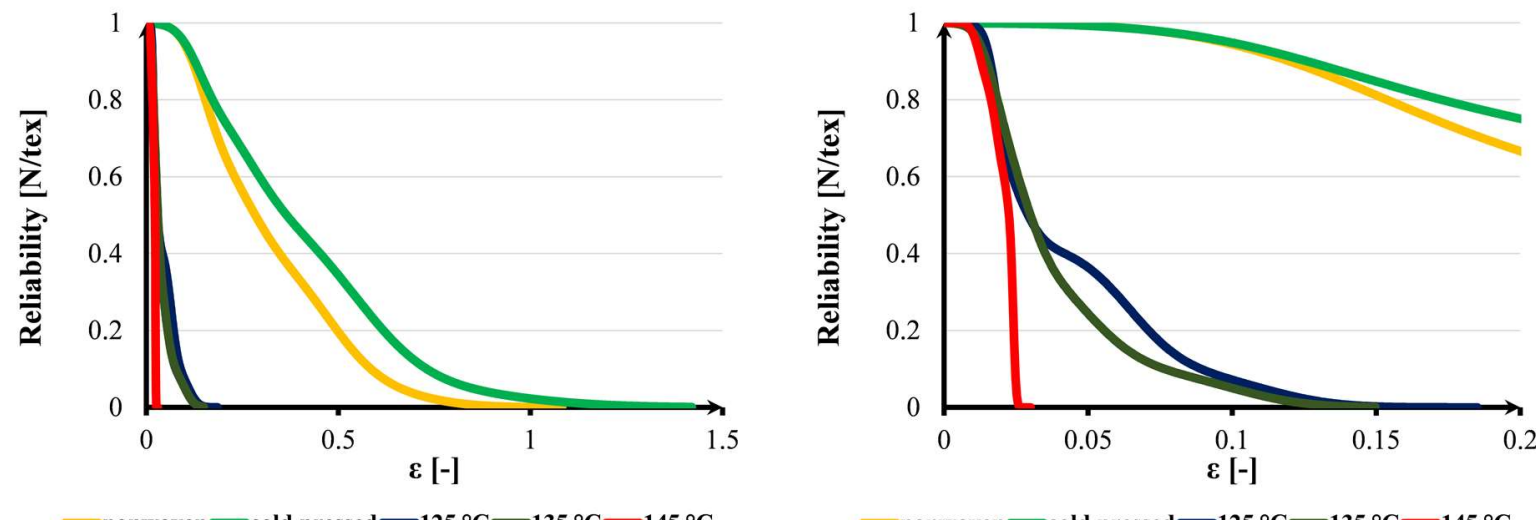

Figure 11: The reliability functions of the examined samples 

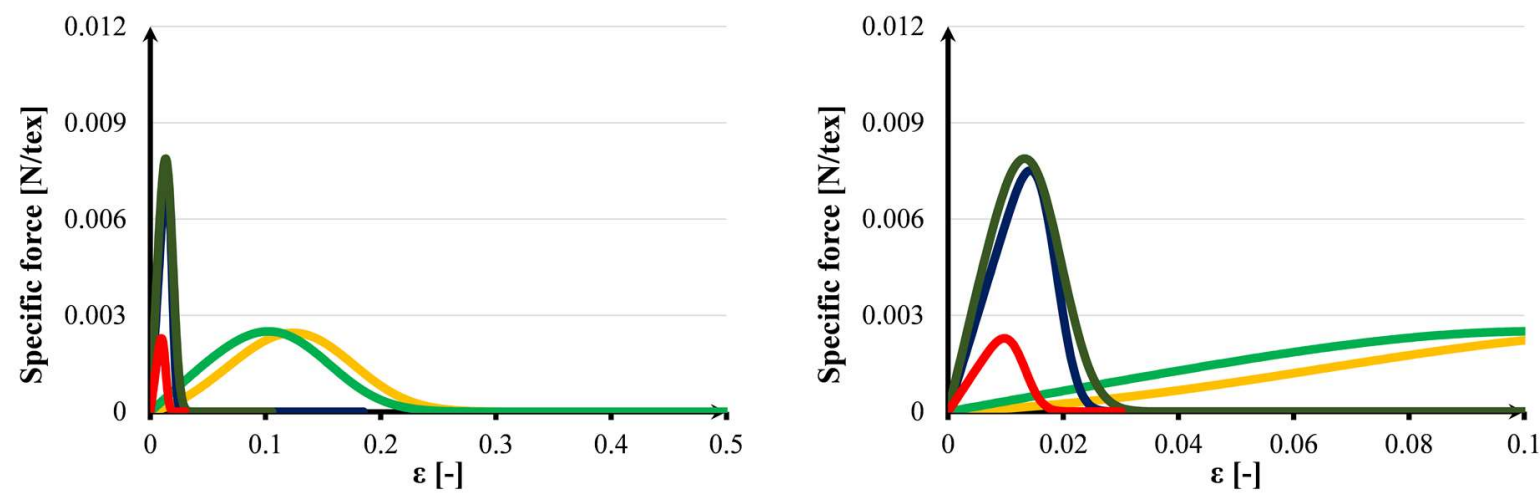

nonwoven $=$ cold pressed $\longrightarrow 125^{\circ} \mathrm{C} \longrightarrow 135^{\circ} \mathrm{C} \longrightarrow 145^{\circ} \mathrm{C}$

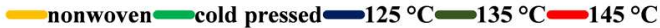

a)
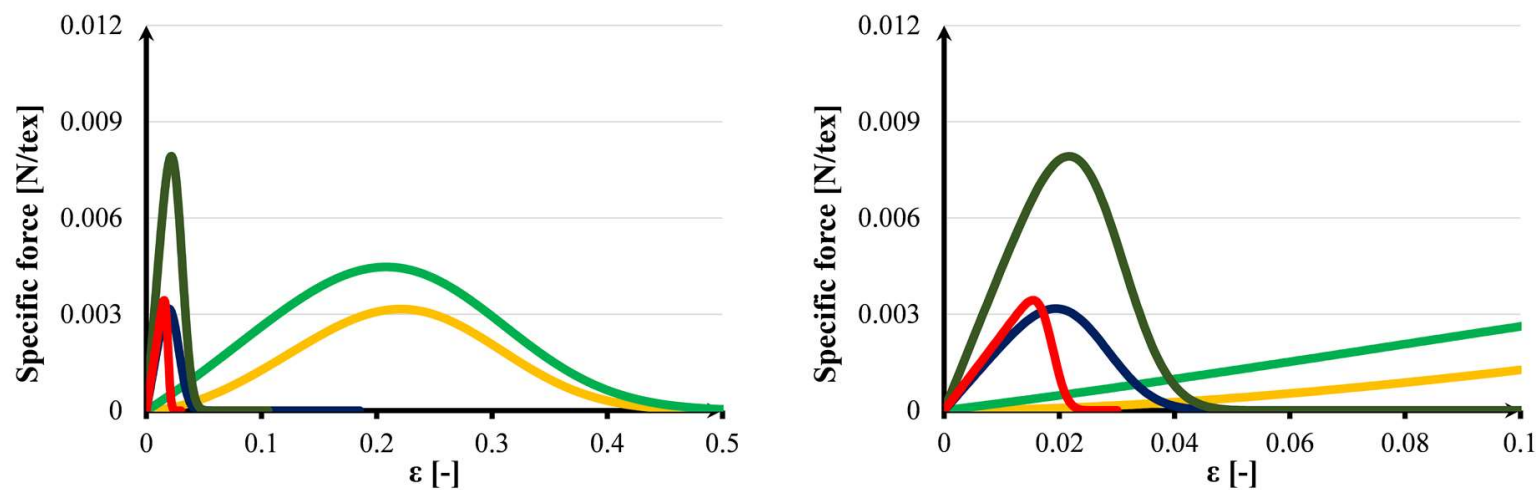

nonwoven $=$ cold pressed $\longrightarrow 125^{\circ} \mathrm{C} \longrightarrow 135^{\circ} \mathrm{C} \longrightarrow 145^{\circ} \mathrm{C}$

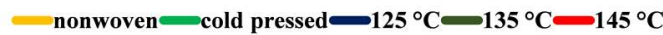

b)
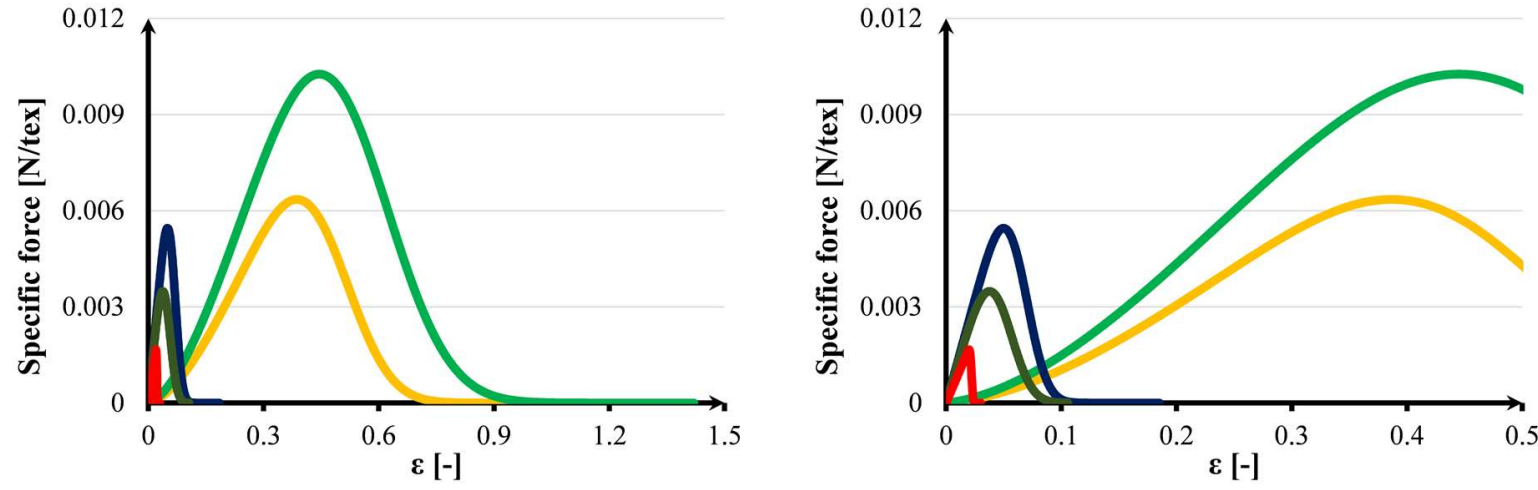

nonwoven $\longrightarrow$ cold pressed $\longrightarrow 125^{\circ} \mathrm{C} \longrightarrow 135^{\circ} \mathrm{C} \longrightarrow 145^{\circ} \mathrm{C}$

c) 

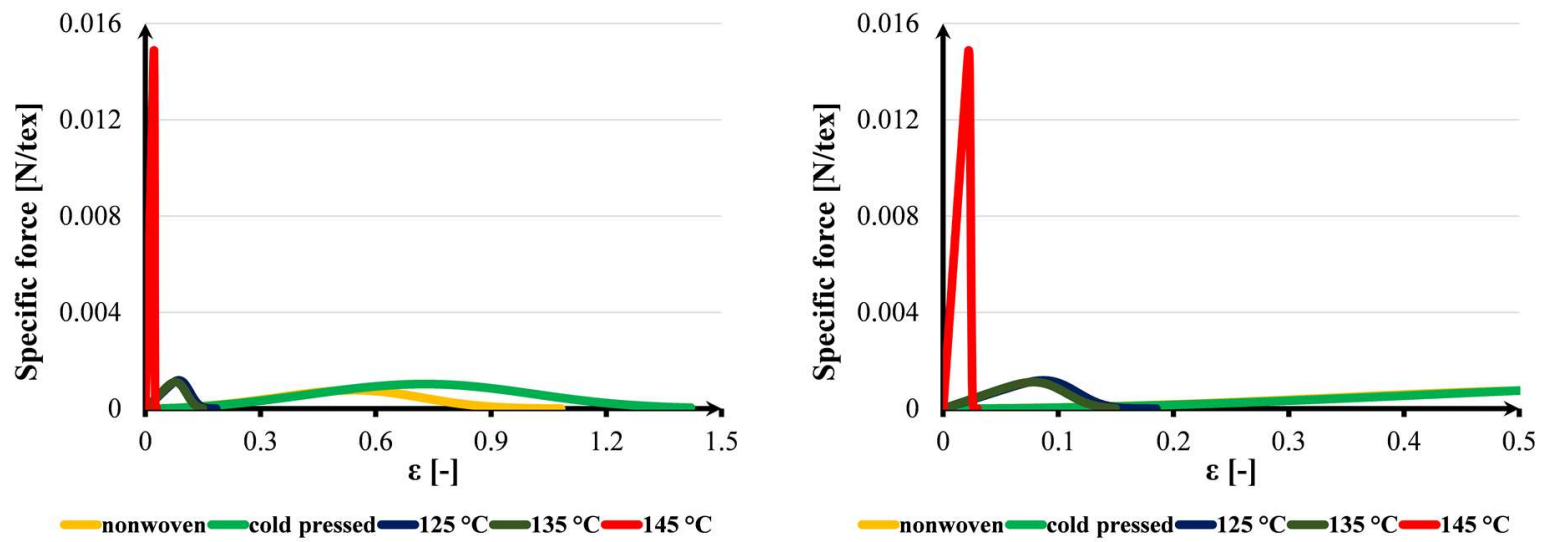

d)

Figure 12: The individual model components denoted by the same serial number (a: component no. 1, b: component no. 2, c: component no. 3 , d: component no. 4) 